\title{
Editorial
}

CARDIOLOGY

\section{Essays on Citation Classics in Cardiology}

\author{
Harisios Boudoulas
}

The Ohio State University, Columbus, Ohio, USA; Biomedical Research Foundation Academy of Athens, Athens, and

Aristotelian University of Thessaloniki, Thessaloniki, Greece

\section{Definition of a Citation Classic}

The number of times a paper is cited is one of the major indicators of its value to the scientific community. So a highly cited publication is considered a citation classic. The number of citations for a given paper, however, depends not only on its scientific significance, but also on the field that it covers. For example, a paper related to biochemistry may have more citations than a paper related to botany even if they have the same scientific significance. Current Contents in 1977 first published essays related to papers that had come to be considered citation classics. The intent was to discuss how publications by now considered citation classics were initiated, whether any obstacles were encountered and to provide insight on why a particular work was cited so much [1].

The new section in Cardiology, Citation Classics, has a novel approach, extending the concept of citation classics specifically to the field of cardiology by involving articles previously published in the journal. The essays involve analysis of the original paper and discussion of developments that have occurred on the topic since the original publication.

In addition to the essay, the original publication (i.e. the citation classic) will be available in electronic format in the same issue of the journal. Essays will be written by one of the authors of the original paper or their former students or colleagues, or else by an expert in the field who can provide an important perspective on the paper.
This will allow the reader to appreciate the evolution of knowledge and concepts in the area of the original article, based on work that has been achieved since it was first published, in line with progress in medical science and technology. Obviously, the longer the time from the original publication, the greater the changes that are to be seen. It may become evident that, with the advances in technology, the interpretation of the physiological/pathophysiological phenomena related to a particular disease indeed differs from that of the original paper.

\section{The Significance of Citation Classics}

'If I have seen further, it is only because I stood on the shoulders of giants'

Isaac Newton, letter to Robert Hooke 1675.

Throughout history, clinicians and researchers have made observations that, over the years, result in a better understanding of basic mechanisms and eventually facilitate the better diagnosis and management of different diseases. Though some research articles get forgotten almost immediately after publication, others have gone on to influence significant discoveries and thereby change the world. The researchers' innovations that have resulted in citation classics were not only for the past but also for time yet to come. We can see further today, thanks to the work of such giants having been published.

\section{KARGER}

E-Mail karger@karger.com

www.karger.com/crd
C 2014 S. Karger AG, Basel

0008-6312/14/1274-0263\$39.50/0
Prof. Harisios Boudoulas, MD, Dr., Dr. Hon

25 Zaimi

GR-55337 Triandria, Thessaloniki (Greece)

E-Mail boudoulas@bioacademy.gr 


\section{Sudden Death}

'And I will say to my soul, Soul, thou hast much goods laid up for many years; take thine ease, eat, drink, and be merry. But God said unto him, Thou fool, this night thy soul shall be required of thee'

St Luke Chapter 12, pp 19-20.

The problem of sudden death, especially in the young, has fascinated scientists and the public for centuries. There was a great deal of dogmatism related to the topic in the past; often, sudden death was considered a punishment from God. Today, however, with new developments in molecular biology and genetics, this phenomenon can be seen from a different perspective. For this reason, the first essay of this new section in Cardiology by Sen-Chowdhry and McKenna [2] is related to sudden cardiac death. It can be seen that even in the short interval since the original publication, significant progress has been made in relation to sudden cardiac death. Several underlying mechanisms have been defined and effective therapies, although not curative, have been developed to prevent sudden cardiac death, including the use of implantable defibrillators. As the authors state, we are not there yet, but significant progress has been made. I am pleased to be able to introduce, in this issue of Cardiology, the first essay on citation classics in cardiology by two world experts on the topic, Sen-Chowdhry and McKenna [3].

References

1 http://gardfield.library.upenn.edu/classics. html

2 Sen-Chowdhry S, McKenna WJ: Sudden cardiac death in the young: a strategy for prevention by targeted evaluation. Cardiology 2006 105:196-206.

3 Sen-Chowdhry S, McKenna WJ: Are we nearly there yet? Progress in the prevention of sudden cardiac death in the young. Cardiology 2014;127:265-274 